\title{
Demographic features and antibiotic resistance among children hospitalized for urinary tract infection in northwest Iran
}

This article was published in the following Dove Press journal:

Infection and Drug Resistance

10 October 2011

Number of times this article has been viewed

\section{Ziaaedin Ghorashi' \\ Sona Ghorashi² \\ Hassan Soltani-Ahari' \\ Nariman Nezami $^{3}$ \\ 'Department of Pediatrics, \\ Tabriz University of Medical Sciences, \\ ${ }^{2}$ Young Researchers Club, Tabriz \\ Branch, Tabriz Islamic Azad University, \\ ${ }^{3}$ Drug Applied Research Center, \\ Tabriz University of Medical Sciences, \\ Tabriz, Iran}

Correspondence: Nariman Nezami

Clinical Pharmacy Laboratory,

Drug Applied Research Center,

Tabriz University of Medical Sciences,

Pashmineh, Daneshgah Street,

Tabriz, Eastern Azerbaijan,

Iran 5I656658II

Tel +984113363234

Fax +98 4II 336-323 I

Email dr.nezami@gmail.com
Introduction: Urinary tract infection (UTI) is the most common serious bacterial infection during infancy. The aim of the present study was to evaluate demographic characteristics, clinical presentations and findings, and antimicrobial resistance among infants and children hospitalized in Tabriz Children's Hospital, Tabriz, Iran.

Methods: In this descriptive observational study, 100 children who had been admitted with UTI diagnosis to Tabriz Children's Hospital from March 2003 to March 2008 were studied. Demographic characteristics, chief complaints, clinical presentations and findings, urine analysis and cultures, antimicrobial resistance, and sonographic and voiding cystourethrographic reports were evaluated.

Results: The mean age of patients was $35.77 \pm 39.86$ months. The male to female ratio was 0.26 . The mean white blood cell count was $12,900 \pm 5226 / \mathrm{mm}^{3}$. Sixty-two percent of patients had leukocytosis. The most common isolated pathogen was Escherichia coli spp (77\%) followed by Klebsiella spp (10\%), Enterobacter spp (9\%), and Enterococcus spp (4\%). Isolated pathogens were highly resistant to ampicillin, cotrimoxazole, and cephalexin (71\%-96\%), intermediate sensitivity to third-generation cephalosporins, and highly sensitive to ciprofloxacin $(84.4 \%)$, amikacin (83.8\%), and nitrofurantoin $(82.8 \%)$.

Conclusion: The most common pathogen of UTI in the hospitalized children was E. coli spp. The isolated pathogens were extremely resistant to ampicillin, and highly sensitive to ciprofloxacin and amikacin.

Keywords: urinary tract infection, antibiotic, resistance, sensitivity, Escherichia coli

\section{Introduction}

Urinary tract infection (UTI) is the most common serious bacterial infection during infancy, ${ }^{1}$ and many children with UTI are admitted to hospital. ${ }^{2}$ UTI has been considered an important risk factor for the development of progressive renal disease and long-term complications. ${ }^{3}$

UTI mostly occurs during the first year of life in boys, much more commonly in uncircumcised boys. The prevalence of UTI varies with the age. During the first year of life, the male to female ratio range is $2.8-5.4$. Beyond $1-2$ years, there is a striking female preponderance with a 1:10 male to female ratio. ${ }^{4}$

Escherichia coli spp corresponds with 75\%-90\% of all UTIs, followed by Klebsiella spp and Proteus spp species in females, but previous reports have showed that Proteus spp is as common as $E$. coli in UTIs of males aged $>1$ year. Others report a preponderance of Gram-positive organisms in UTIs of males. Staphylococcus saprophyticus and Enterococcus spp are UTI causative pathogens in both sexes. ${ }^{4}$ 
Most of these children receive empirical antibiotic therapy before revealing the causative pathogen and antimicrobial sensitivity and resistance. ${ }^{1}$ Recently, Farrell et $\mathrm{al}^{5}$ demonstrated extremely high resistance to trimethoprim, ampicillin, and cephalosporins, rendering them unsuitable for empirical use. Increasing resistance of bacterial pathogens is of worldwide concern that is varied in different regions and even countries. ${ }^{1,5}$ Such reports show that continued surveillance and investigation of other oral agents for treatment of UTI in the community is required. ${ }^{4}$ A recent study by Mortazavi and Shahin ${ }^{6}$ in the Azerbaijan region showed that the prevalence of bacterial cause of UTI and resistance to antibacterial regimes changed from 2000 to 2007. So, the present study aimed to evaluate demographic characteristics, clinical presentations and findings, and especially antimicrobial resistance among infants and children hospitalized due to UTI in northwest Iran's referral center, Tabriz Children's Hospital, Tabriz, Iran.

\section{Materials and methods}

\section{Study design and population}

The present descriptive observational study was carried out in the infectious disease ward of Tabriz Children's Hospital. From March 2003 to March 2008, 230 patients were hospitalized with a principal diagnosis of UTI. Hospital records for these children were studied and finally the complete data of 100 patients were collected. Age (months for patients aged $<2$ years and years for patients aged $>2$ years), gender, weight, history of previous hospitalization, chief complaint, clinical presentation, body temperature, duration of hospitalization, outcome, white blood cell (WBC) count, erythrocytes sedimentation rate (ESR), C-reactive protein (CRP), urine analysis and culture, empirically used antibiotics, antibiotic resistance and sensitivity, sonography, and voiding cystourethrography were extracted.

All participants signed informed written consent and the study protocol was approved by the Ethics Committee of Tabriz University of Medical Sciences, which was in compliance with the Helsinki declaration.

\section{Sample collection and tests performed}

The inclusion criteria were diagnosis of UTI and availability of complete documentation. Change in diagnosis, presence of genitourinary abnormalities (except vesicoureteral reflux [VUR]), and loss of any study variables were considered criteria for exclusion.

Urine samples were collected by suprapubic aspiration in neonates, urine bag (using sterile method) in infants aged 1 month to 2.5 years, and midstream urine in children aged $>2.5$ years. Diagnosis of UTI was defined as any colony-forming units/mL of a single organism on a suprapubic aspiration method, or $\geq 10^{5}$ colony-forming units $/ \mathrm{mL}$ on a clean-catch specimen of freshly voided urine using urine bag and midstream methods. Urine culture, antimicrobial susceptibility tests, and interpretation were done using Clinical and Laboratory Standards Institute guidelines. ${ }^{7}$ These samples were processed on blood agar and MacConkey agar medium (HiMedia Laboratories Pvt Ltd, Mumbai, India) with a standard loop and then were incubated at $37^{\circ} \mathrm{C}$ overnight. Antimicrobial susceptibility and resistance testing was performed by the disk diffusion method on cultures using antibiotic disks (PADTAN TEB antimicrobial susceptibility test disks; Padtan-Teb Co, Tehran, Iran). All laboratory tests were done in the laboratory of Tabriz Children's Hospital.

Leukocytosis was defined according to the age of patients. ${ }^{8}$ Presence of more than five WBCs in one light microscopic field was considered as active urine analysis. ${ }^{9}$ CRP was determined using an ENISON CRP latex commercial kit (Enison Lab and Pharmaceutical Industries, Tehran, Iran). Cutoff values for CRP were +1 for $10-25 \mathrm{mg} / \mathrm{L},+2$ for $25-50 \mathrm{mg} / \mathrm{L}$, and +3 for $>50 \mathrm{mg} / \mathrm{L}$.

\section{Statistical analysis}

Statistical analysis was performed using the SPSS (v 13.0; SPSS Inc, Chicago, IL) software package. Quantitative data are presented as mean \pm standard deviation, while qualitative data are demonstrated as frequency and percent. The statistical tests for comparison were chi-square test, independent sample $t$-test, and one-way analysis of variance test. A $P$-value of less than 0.05 was considered statistically significant.

\section{Results}

Data from 100 patients were completely extracted and analyzed. The mean age of infants $(<2$ years $)$ was $9.39 \pm 5.89$ months, and the mean age of children ( $\geq 2$ years) was $6.30 \pm 3.01$ years. Twenty-one patients were male (21\%) and 79 were female (79\%). Male to female ratio in all patients, in patients aged $<1$ year, aged between 1 and 2 years, and $>2$ years were $21: 79,12: 32,4: 12$, and 5:35, respectively. Thirty-eight patients had positive history of hospitalization; 24 were hospitalized for the first time (24\%), four for the second time (4\%), three for the third time (3\%), five for the fourth time (5\%), and two for the fifth time (2\%).

The mean body weight of studied patients was $11.79 \pm 7.53 \mathrm{~kg}$ (range $2.10-41.00 \mathrm{~kg}$ ). Duration of hospitalization was $7.89 \pm 4.36$ days (range $2-23$ days). The frequency of chief complaints is listed in Table 1. 
Table I Frequency of chief complaint at time of referring to hospital

\begin{tabular}{ll}
\hline Symptoms & Percent \\
\hline Fever & 36 \\
Dysuria & 30 \\
Crying at time of urination & 14 \\
Failure to thrive & 12 \\
Diarrhea & 9 \\
Anorexia & 7 \\
Flank pain & 7 \\
Frequency & 6 \\
Vomiting & 3 \\
Hematuria & 3 \\
Malodorous urine & 3 \\
Poor feeding & 3 \\
Abdominal pain & 3 \\
\hline
\end{tabular}

The mean body temperature at time of admission was $37.84^{\circ} \mathrm{C} \pm 0.97^{\circ} \mathrm{C}$ (range $36^{\circ} \mathrm{C}-41.5^{\circ} \mathrm{C}$ ). Forty-two percent of patients had fever. Mean body temperature for patients with and without fever was $38.94^{\circ} \mathrm{C} \pm 0.60^{\circ} \mathrm{C}$ and $37.27^{\circ} \mathrm{C} \pm 0.55^{\circ} \mathrm{C}$, respectively $(P=0.002)$.

The mean WBC count was $12,900 \pm 5226 / \mathrm{mm}^{3}$ (range $\left.4300-28,500 / \mathrm{mm}^{3}\right)$. Sixty-two percent of patients had leukocytosis. CRP was negative in 55 patients $(55 \%) ;+1$ in 17 patients (17\%), +2 in 21 patients $(21 \%),+3$ in six patients $(6 \%)$, and +4 in one patient (1\%). The mean first-hour ESR level was $38.74 \pm 30.82 \mathrm{~mm} /$ hour (range $2-120 \mathrm{~mm} /$ hour).

Ninety-two patients $(92 \%)$ had active urine analysis (more than five WBC per field). More than five red blood cells per field were reported for 15 patients $(15 \%)$. The most common isolated pathogen was E. coli $(77 \%)$, followed by Klebsiella spp (10\%), Enterobacter spp (9\%), and Enterococcus spp (4\%).
Antibiotic resistances are shown in Table 2. Sonographic findings were normal in 66 patients (66\%). Abnormal findings were unilateral in 25 patients and bilateral in five patients. Increased thickness of bladder wall and ascites were reported in two patients each. Sonographic findings are shown in Table 3.

Forty-two patients underwent cystourethrography during hospitalization (42\%). Thirteen patients were advised to complete it as outpatients (13\%), but 45 did not undergo cystourethrography (45\%). Of 42 patients, 18 had normal findings (43\%). Fourteen patients had VUR (14\%) and nine patients had bilateral VUR (9\%). Neurogenic bladder was reported in one patient (1\%). Cystourethrographic findings are listed in Table 4.

Table 5 shows the comparison of demographic, clinical, and laboratory findings according to cause of UTI. As demonstrated, there was no significant difference between causes of UTI in the case of male to female ratio, infant to child ratio, age, weight, body temperature, fever, WBC, leukocytosis, first-hour ESR, and duration of hospitalization.

\section{Discussion}

UTI is recognized increasingly as a common cause of fever in young children. ${ }^{10-12}$ However, clinical findings indicating UTI in this group of patients are often subtle and nonspecific, with fever often being the only finding. ${ }^{13}$ During the present study, fever was recognized as the most common unspecific symptom of UTI.

Clinical UTI is characterized by any or all of the following: abdominal or flank pain, fever, malaise, nausea, vomiting, and, occasionally, diarrhea. Newborns may show nonspecific symptoms such as poor feeding, irritability, and weight loss. ${ }^{4}$

Table 2 Antibiotic resistance of isolated pathogens

\begin{tabular}{lllll}
\hline Antibiotic & Resistance (\%) & & & Klebsiella spp \\
\cline { 2 - 5 } & Escherichia coli & 100 & Enterobacter spp & Enterococcus spp \\
\hline Ampicillin & 94.7 & 90 & 100 & 100 \\
Cotrimoxazole & 71.1 & 80 & 66.7 & 75 \\
Cephalexin & 68.4 & 60 & 77.8 & - \\
Gentamicin & 36.1 & 40 & 37.5 & 100 \\
Nalidixic acid & 33.3 & 75 & 22.2 & 75 \\
Ceftazidime & 27.6 & 60 & 0 & - \\
Ceftizoxime & 26.3 & 60 & 22.2 & - \\
Ceftriaxone & 22.4 & 50 & 33.3 & - \\
Cefotaxime & 22.7 & 50 & 22.2 & - \\
Cefixime & 22.4 & - & 22.2 & - \\
Vancomycin & - & 40 & - & 0 \\
Nitrofurantoin & 14.5 & 10 & 11.1 & 25 \\
Amikacin & 11.8 & 10 & 22.2 & - \\
Ciprofloxacin & 14.5 & 0 & 75 \\
\hline
\end{tabular}


Table 3 Frequency of sonographic findings

\begin{tabular}{llll}
\hline & $\begin{array}{l}\text { Right kidney } \\
\text { N (\%) }\end{array}$ & $\begin{array}{l}\text { Left kidney } \\
\text { N (\%) }\end{array}$ & P* \\
\hline Hydronephrosis & I $2(12)$ & I $3(13)$ & NS \\
Atrophy and hydronephrosis & I (I) & I (I) & NS \\
Hypoplasia & I (I) & $2(2)$ & NS \\
Renal stones & $3(3)$ & $3(3)$ & NS \\
Ureteral occlusion & $0(0)$ & I (I) & NS
\end{tabular}

Note: *Chi-square test was used.

Abbreviation: NS, not significant.

In the present study, UTI clinically presented most commonly with fever followed by dysuria, crying at time of urination, failure to thrive, diarrhea, anorexia, flank pain, and frequency. Abdominal or flank pain and nausea/vomiting were not as frequent as reported before. ${ }^{4}$ Also, dysuria and diarrhea were among the common clinical presentations of UTI in this study.

Demographic findings were consistent with previous studies. $^{2-4,13-15}$ The proportion of UTI in females was higher than in males after the first year of life. The male to female ratio during the first year of life has previously been reported as 2.8-5.4:1, while the results of the present study had a lower ratio. Striking female preponderance with a male to female ratio of $1: 10$ has been reported in patients with UTI aged beyond 1-2 years. ${ }^{4}$ Such findings have been reported in the present study.

VUR caused by retrograde urine flow from the bladder to the kidneys can culminate in recurrent UTI, severe renal complications, and end stage renal failure. ${ }^{15-18}$ As kidney damage resulting from severe VUR is preventable, early detection, follow-up, and proper management of underlying lower urinary tract abnormalities are desirable. ${ }^{19,20}$ In the present study, VUR has been revealed in 31 kidney-ureter units as the risk factor of UTI (31\%).

In the present study, E. coli was isolated from $77 \%$ of patients as the common pathogen of UTI, similar to Mathai et al's ${ }^{21}$ study findings. The emergence of resistant bacteria is a significant problem in UTI chemotherapy. In

Table 4 Frequency of cystourethrographic findings

\begin{tabular}{lllll}
\hline & & Right kidney & Left kidney & P* \\
& N (\%) & N (\%) & \\
\hline Reflux & Grade I & $2(2)$ & $3(3)$ & NS \\
& Grade II & $2(2)$ & $2(2)$ & NS \\
Grade III & $8(8)$ & $7(7)$ & NS \\
& Grade IV & $3(3)$ & $2(2)$ & NS \\
& Grade V & $2(2)$ & $0(0)$ & NS \\
\hline
\end{tabular}

Note: ${ }^{*}$ Chi-square test was used.

Abbreviation: NS, not significant.
Japan, isolation of fluoroquinolone-resistant E. coli from patients with UTI is reported as a serious therapeutic problem. ${ }^{22}$ In the present study, E. coli showed $88.3 \%, 67.5 \%$, and $57.1 \%$ resistance to ampicillin, cotrimoxazole, and cephalexin, respectively. In most studies in Canada, Europe, Africa, Turkey, Spain, Taiwan, and Israel, the majority of isolated pathogens were resistant to ampicillin and cotrimoxazole. ${ }^{23-25}$ The present study results showed that the best activity against E. coli was achieved with amikacin, nitrofurantoin, and ciprofloxacin, followed by third-generation cephalosporins. These results are consistent with Yuksel et $\mathrm{al}^{23}$ and Turnidge et $\mathrm{al}^{25}$

Klebsiella spp had a varying antibiotic resistance and showed higher resistance to ampicillin (100\%), cotrimoxazole (90\%), and cephalexin (80\%). Also, Klebsiella spp had intermediate resistance against ceftriaxone (60\%), cefotaxime $(50 \%)$, and cefixime (50\%), and showed lowest resistance to amikacin (10\%) and ciprofloxacin (10\%). Yuksel et $\mathrm{al}^{24}$ reported a low rate of resistance of Klebsiella spp against amikacin (50\%) and ciprofloxacin (50\%), and a higher level of resistance against ampicillin (82\%). Sensitivity of Klebsiella spp to cotrimoxazole in the present study was $10 \%$, while other studies reported $65 \%-75 \%$ sensitivity to this antibiotic ${ }^{22,24}$ due to uncontrolled administration of the drug.

Enterobacter spp has the lowest prevalence as a UTI pathogen. ${ }^{23}$ In the present study, the prevalence of this Gramnegative bacteria is reported at about $9 \%$, with excessive resistance to ampicillin (100\%), higher resistance to firstgeneration cephalosporins (cephalexin), and mild resistance to third-generation cephalosporins, consistent with Tunidge et al's ${ }^{25}$ and Catal et al's ${ }^{26}$ results. Resistance by the extended spectrum betalactamase (ESBL) mechanism is an important emerging problem in Enterobacter spp. ${ }^{27,28}$ ESBLs are betalactamase that hydrolyze penicillin and extended spectrum cephalosporins with an oxyimino side chain that includes ceftazidime, ceftriaxone, cefotaxime, and aztreonam. Antibiotic utilization patterns, including widespread cephalosporin use, have been associated with the emergence of ESBLs and a decrease of administration of these antibiotics has been associated with control of ESBL emergence. ${ }^{29,30}$ The antibiotic resistance rate of Enterobacter spp to ciprofloxacin is low in children, due to the rarity of its administration. In contrast to Caksen et al's ${ }^{31}$ findings, unfortunately, $100 \%$ of isolated Enterobacter spp were resistant to ciprofloxacin in the present study.

In this study, $4 \%$ of UTI pathogens were Enterococcus spp; its prevalence was similar to Muratani and Matsumoto's ${ }^{22}$ report. Findings in this study showed that isolated Enterococcus spp 
Table 5 Comparison of demographic, clinical, and laboratory findings according to cause of UTI

\begin{tabular}{|c|c|c|c|c|c|}
\hline & $\begin{array}{l}\text { Escherichia coli } \\
(N=77)\end{array}$ & $\begin{array}{l}\text { Klebsiella } \\
(\mathrm{N}=10)\end{array}$ & $\begin{array}{l}\text { Enterobacter } \\
(\mathbf{N}=\mathbf{9})\end{array}$ & $\begin{array}{l}\text { Enterococcus } \\
(\mathbf{N}=\mathbf{4})\end{array}$ & $P$ \\
\hline Male to female ratio & $14: 63$ & $3: 7$ & $3: 6$ & $\mathrm{I}: 3$ & $0.632 *$ \\
\hline Infant to child ratio & $42: 35$ & $9: 1$ & $5: 4$ & $4: 0$ & $0.059 *$ \\
\hline Infant age (months) & $9.98 \pm 6.06$ & $7.16 \pm 5.50$ & $7.70 \pm 4.99$ & $10.25 \pm 6.34$ & $0.540^{\S}$ \\
\hline Child age (years) & $6.54 \pm 3.09$ & 4 (I case) & $4.75 \pm 2.06$ & - & $0.405^{\S}$ \\
\hline Weight (kg) & $12.67 \pm 7.89$ & $6.33 \pm 2.97$ & $11.82 \pm 7.03$ & $8.57 \pm 2.23$ & $0.069 \S$ \\
\hline Body temperature $\left({ }^{\circ} \mathrm{C}\right)$ & $37.77 \pm 0.92$ & $37.67 \pm 0.76$ & $38.61 \pm 1.45$ & $37.87 \pm 0.62$ & $0.099 \S$ \\
\hline Fever $(\mathrm{N})$ & 24 & 3 & 6 & 1 & $0.189 *$ \\
\hline WBCs $\left(/ \mathrm{mm}^{3}\right)$ & $13,250 \pm 5702$ & $11,960 \pm 2825$ & $11,944 \pm 3437$ & $|0,675 \pm 260|$ & $0.644^{\S}$ \\
\hline Leukocytosis $(\mathrm{N})$ & 49 & 5 & 6 & 2 & $0.795^{*}$ \\
\hline First-hour ESR (mm/hour) & $41.03 \pm 30.71$ & $22.30 \pm 19.81$ & $45.44 \pm 39.83$ & $20.75 \pm 20.83$ & $0.167^{\S}$ \\
\hline Duration of hospitalization (days) & $7.71 \pm 4.60$ & $8.50 \pm 3.65$ & $8.87 \pm 3.11$ & $7.75 \pm 4.50$ & $0.877^{\S}$ \\
\hline
\end{tabular}

Notes: *Chi-square test; §one-way analysis of varience test.

Abbreviations: UTI, urinary tract infection; WBCs, white blood cells; ESR, erythrocytes sedimentation rate.

were extremely (100\%) resistant to ampicillin and gentamicin. Such high resistance to these antibiotics has been reported previously by other authors. ${ }^{31}$ Sensitivity of Enterococcus spp to vancomycin and nitrofurantoin was $100 \%$ and $75 \%$, respectively, which was consistent with Mathai et al's ${ }^{21}$ and Turnidge et al's ${ }^{25}$ findings.

Comparing the present study with a recent study by Mortazavi and Shahin ${ }^{6}$ in East Azerbaijan, demographic characteristics and prevalence of bacterial causes of UTI did not change. Comparing the antibacterial resistance of E. coli to Mortazavi and Shahin's study, resistance to ampicillin increased and resistance to gentamicin, nalidixic acid, ceftazidime, and cefixime decreased but remained unchanged against other antibiotics. Also, Klebsiella spp showed increased antibacterial resistance against nalidixic acid, cefixime, and cotrimoxazole, and decreased resistance to amikacin and nitrofurantoin.

Finally, the present study was a small, regional retrospective study and results show that there is a need for large longitudinal national studies to determine prevalence, demographic characteristics, possible etiology, and antibiotic resistance. The present study has also evaluated the pattern of antibiotic resistance among hospitalized children with diagnosis of UTI, which provides important information concerning this region.

\section{Conclusion}

E. coli is the most common isolated bacterium in hospitalized children with a principal diagnosis of UTI. Most of the isolated pathogens are highly resistant to ampicillin, cotrimoxazole, and cephalexin $(71 \%-96 \%)$, have intermediate sensitivity to thirdgeneration cephalosporins, and high sensitivity to ciprofloxacin $(84.4 \%)$, amikacin $(83.8 \%)$, and nitrofurantoin $(82.8 \%)$.

\section{Acknowledgment}

The authors wish to express their gratitude to the patients and their parents participating in this report.

\section{Disclosure}

Written informed consent was obtained for publication from the patients' parents. The authors report no conflicts of interest in this work.

\section{References}

1. Lutter SA, Currie ML, Mitz LB, Greenbaum LA. Antibiotic resistance patterns in children hospitalized for urinary tract infections. Arch Pediatr Adolesc Med. 2005;159(10):924-928.

2. Spencer JD, Schwaderer A, McHugh K, Hains DS. Pediatric urinary tract infections: an analysis of hospitalizations, charges, and costs in the USA. Pediatr Nephrol. 2010;25(12):2469-2475.

3. Christensen A, Shaw KN. Urinary tract infection in childhood. In: Laplan BS, Meyers KE, editors. Pediatric Nephrology and Urology: The Requisites in Pediatrics. Philadelphia: Elsevier Mosby; 2004:317-325.

4. Elder JS. Urinary tract infections. In: Kliegman RM, Behrman RE, Jenson HB, Stanton B, editors. Nelson Textbook of Pediatrics. 18th ed. Philadelphia: Saunders Elsevier; 2007:2223-2227.

5. Farrell DJ, Morrissey I, De Rubeis D, Robbins M, Felmingham D. A UK multicentre study of the antimicrobial susceptibility of bacterial pathogens causing urinary tract infection. J Infect. 2003;46(2):94-100.

6. Mortazavi F, Shahin N. Changing patterns in sensitivity of bacterial uropathogens to antibiotics in children. Pak J Med Sci. 2009;25(5):801-805.

7. Clinical and Laboratory Standards Institute (CLSI). Performance Standards for Antimicrobial Disk Susceptibility Tests; Approved Standard: Tenth Edition. MO2-A10. Wayne, PA: CLSI; 2009.

8. Lanzkowsky P. Manual of Pediatric Hematology and Oncology. 4th ed. Burlington: Elsevier Academic Press; 2005.

9. Fuller CH, Threatte GA, Henry JB. Basic examination of urine. In: Henry JB, editor. Clinical Diagnosis and Management by Laboratory Methods. 20th ed. Philadelphia: WB Saunders; 2001:367-402.

10. Shaw KN, Gorelick M, McGowan KL, Yakscoe NM, Schwartz JS. Prevalence of urinary tract infection in febrile young children in the emergency department. Pediatrics. 1998;102(2):e16.

11. Hoberman A, Chao HP, Keller DM, Hickey R, Davis HW, Ellis D. Prevalence of urinary tract infection in febrile infants. $J$ Pediatr. 1993;123(1):17-23. 
12. Bauchner H, Philipp B, Dashefsky B, Klein JO. Prevalence of bacteriuria in febrile children. Pediatr Infect Dis J. 1987;6(3):239-242.

13. Gorelick MH, Shaw KN. Screening tests for urinary tract infection in children: a meta-analysis. Pediatrics. 1999;104(5):e54.

14. Alper BS, Curry SH. Urinary tract infection in children. Am Fam Physician. 2005;72(12):2483-2488.

15. Cooper CS. Diagnosis and management of vesicoureteral reflux in children. Nat Rev Urol. 2009;6(9):481-489.

16. Murer L, Benetti E, Artifoni L. Embryology and genetics of primary vesico-ureteric reflux and associated renal dysplasia. Pediatr Nephrol. 2007;22(6):788-797.

17. Murawski IJ, Gupta IR. Vesicoureteric reflux and renal malformations: a developmental problem. Clin Genet. 2006;69(2):105-117.

18. Malaki M, Sayedzadeh SA, Shoaran M. Growth indices in urinary tract infection children with or without vesicoureteral reflux. Saudi J Kidney Dis Transpl. 2011;22(4):723-726.

19. Merrick MV, Notghi A, Chalmers N, Wilkinson AG, Uttley WS. Long-term follow up to determine the prognostic value of imaging after urinary tract infections. Part 2: scarring. Arch Dis Child. 1995;72(5):393-396.

20. Nuutinen $M$, Uhari $M$. Recurrence and follow-up after urinary tract infection under the age of 1 year. Pediatr Nephrol. 2001;16(1):69-72.

21. Mathai D, Jones RN, Pfaller MA. Epidemiology and frequency of resistance among pathogens causing urinary tract infections in 1,510 hospitalized patients: a report from the SENTRY Antimicrobial Surveillance Program (North America). Diagn Microbiol Infect Dis. 2001;40(3):129-136.

22. Muratani T, Matsumoto T. Bacterial resistance to antimicrobials in urinary isolates. Int J Antimicrob Agents. 2004;24 Supp1 1:S28-S31.
23. Kurutepe S, Surucuoglu S, Sezgin C, Gazi H, Gulay M, Ozbakkaloglu B. Increasing antimicrobial resistance in Escherichia coli isolates from community-acquired urinary tract infections during 1998-2003 in Manisa, Turkey. Jpn J Infect Dis. 2005;58(3):159-161.

24. Yuksel S, Ozturk B, Kavaz A, et al. Antibiotic resistance of urinary tract pathogens and evaluation of empirical treatment in Turkish children with urinary tract infections. Int J Antimicrob Agents. 2006;28(5):413-416.

25. Turnidge J, Bell J, Biedenbach DJ, Jones RN. Pathogen occurrence and antimicrobial resistance trends among urinary tract infection isolates in the Asia-Western Pacific Region: report from the SENTRY Antimicrobial Surveillance Program, 1998-1999. Int J Antimicrob Agents. 2002;20(1):10-17.

26. Catal F, Bavbek N, Bayrak O, et al. Antimicrobial resistance patterns of urinary tract pathogens and rationale for empirical therapy in Turkish children for the years 2000-2006. Int Urol Nephrol. 2009;41(4):953-957.

27. Patterson JE. Extended spectrum beta-lactamases: a therapeutic dilemma. Pediatr Infect Dis J. 2002;21(10):957-959.

28. Bonnet R. Growing group of extended-spectrum beta-lactamases: the CTX-M enzymes. Antimicrob Agents Chemother. 2004;48(1):1-14.

29. Patterson JE, Hardin TC, Kelly CA, Garcia RC, Jorgensen JH. Association of antibiotic utilization measures and control of multipledrug resistance in Klebsiella pneumoniae. Infect Control Hosp Epidemiol. 2000;21(7):455-458.

30. Toltzis P, Dul M, O'Riordan MA, et al. Cefepime use in a pediatric intensive care unit reduces colonization with resistant bacilli. Pediatr Infect Dis J. 2003;22(2):109-114.

31. Caksen H, Cesur Y, Uner A, et al. Urinary tract infection and antibiotic susceptibility in malnourished children. Int Urol Nephrol. 2000;32(2):245-247.
Infection and Drug Resistance

\section{Publish your work in this journal}

Infection and Drug Resistance is an international, peer-reviewed openaccess journal that focuses on the optimal treatment of infection (bacterial, fungal and viral) and the development and institution of preventive strategies to minimize the development and spread of resistance. The journal is specifically concerned with the epidemiology of antibiotic

\section{Dovepress}

resistance and the mechanisms of resistance development and diffusion in both hospitals and the community. The manuscript management system is completely online and includes a very quick and fair peerreview system, which is all easy to use. Visit http://www.dovepress.com/ testimonials.php to read real quotes from published authors. 